\title{
Assessing pest control using changes in instantaneous rate of population increase: Treated targets and stable fly populations case study
}

\author{
D. V. Beresford ${ }^{1}$ and J. F. Sutcliffe \\ Trent University Biology Department, 1600 West Bank Drive, Peterborough, Ontario, Canada K9J 7B8
}

\begin{abstract}
The instantaneous rate of population increase was used to assess the ability of attractive targets coated with permethrin to control stable fly populations on 3 dairy farms in south central Ontario, Canada. Two attractive targets were deployed over $10 \mathrm{wk}$ in 2001 at each of 6 dairy farms. Three farms were outfitted with 2 untreated targets and 3 were outfitted with 2 targets treated with permethrin [Ectiban-impregnated Coroplast (Ectiban: Schering-Plough Canada Inc., PointeClaire, Québec, Canada; Coroplast: Great Pacific Enterprises Inc., Granby, Québec, Canada)]. Population growth rate was measured in terms of degree-days above a $10^{\circ} \mathrm{C}$ developmental threshold $\left(r_{\mathrm{DD} 10}\right)$. The $r_{\mathrm{DD} 10}$ at the 3 treated dairy farms were significantly lower than $r_{\mathrm{DD} 10}$ at the 3 neighboring untreated dairy farms (mean $r_{\mathrm{DD} 10}$ : treated $=0.0088$, untreated $\left.=0.013\right)$, but not in the previous year when targets were not installed (mean $r_{\mathrm{DD} 10}$ : treated $=0.012$, untreated $\left.=0.015\right)$. This supports a long-term approach to management that lowers population growth rates in those regions where stable fly numbers increase exponentially from spring until winter, by shortening the period of economic impact of this pest.
\end{abstract}

Key words: stable fly, Stomoxys calcitrans, instantaneous rate of population increase, treated target

\section{INTRODUCTION}

An underused metric for assessing the success of pest control strategies is the instantaneous rate of population increase ( $\boldsymbol{r}$; Stark and Banks, 2003). This is a direct measure of population growth rate in exponentially growing populations (Frazer, 1972; Stark and Banks, 2003), obtained as the slope of the regression line of $\ln \mathrm{N}(\mathrm{N}=$ population size $)$ versus time of year. Unlike the intrinsic rate of increase $\left(\boldsymbol{r}_{m}\right)$, which measures the potential growth rate of a species based on life history parameters, $r$ is an appropriate trait for pest control

Received November 7, 2009.

Accepted February 25, 2010.

${ }^{1}$ Corresponding author: david.beresford2@sympatico.ca studies because it measures observed growth rates, incorporating the effects of control measures on both survival and fecundity.

One possible explanation for why $r$ may be rejected as a suitable metric is that pest populations often appear to grow at different rates throughout the season, increasing rapidly at first until peaking at mid summer, then decreasing afterward (Figure 1a). However, this perceived pattern of changing growth rates may simply be an artifact of sampling design (Beresford and Sutcliffe, 2009a), with lower catches in late summer and fall attributable to cooler temperatures producing effectively shorter sampling periods.

For example, consider a model of a population in a temperate region growing exponentially at a rate of $r$ $=0.005$ per degree day (DD) above a $10^{\circ} \mathrm{C}$ developmental threshold ( $\boldsymbol{r}_{\mathrm{DD10}}$; Birch, 1948; Hughes, 1962). If this population is sampled weekly using traps that accumulate catch over the sample period during a typical summer in a temperate zone, catches are obtained over sampling periods that differ each week in terms of physiologically relevant time (i.e., the number of DD). By expressing such data as catch per unit of sampling period (per $\mathrm{DD}_{10}$ each week; Beresford and Sutcliffe, 2009a) and plotting these against the accumulated DD above $10^{\circ} \mathrm{C}\left(\mathbf{A D D}_{10}\right)$, the pattern of exponential growth becomes apparent (Figure 1b). An example of this occurs in stable fly (Stomoxys calcitrans L.) populations on dairy farms in south central Ontario. There, low stable fly numbers begin growing exponentially each spring and continue through the summer until halted by cold autumn temperatures (Beresford and Sutcliffe, 2009a,b).

Stable flies cost the combined dairy and beef industries $>\$ 1$ billion US each year because of reduced milk yield and slower weight gain (Taylor and Berkebile, 2006). As few as 5 stable flies/front leg (Gerry et al., 2007) represents the economic breakeven point (Campbell et al., 1987) between control costs and production loss (i.e., the treatment threshold; Catangui et al., 1997). The decision to begin controlling stable flies by producers is usually based on cattle behavior (Dougherty et al., 1993). On dairy farms in south central Ontario, this occurs in mid to late summer (Beresford and Sutcliffe, 

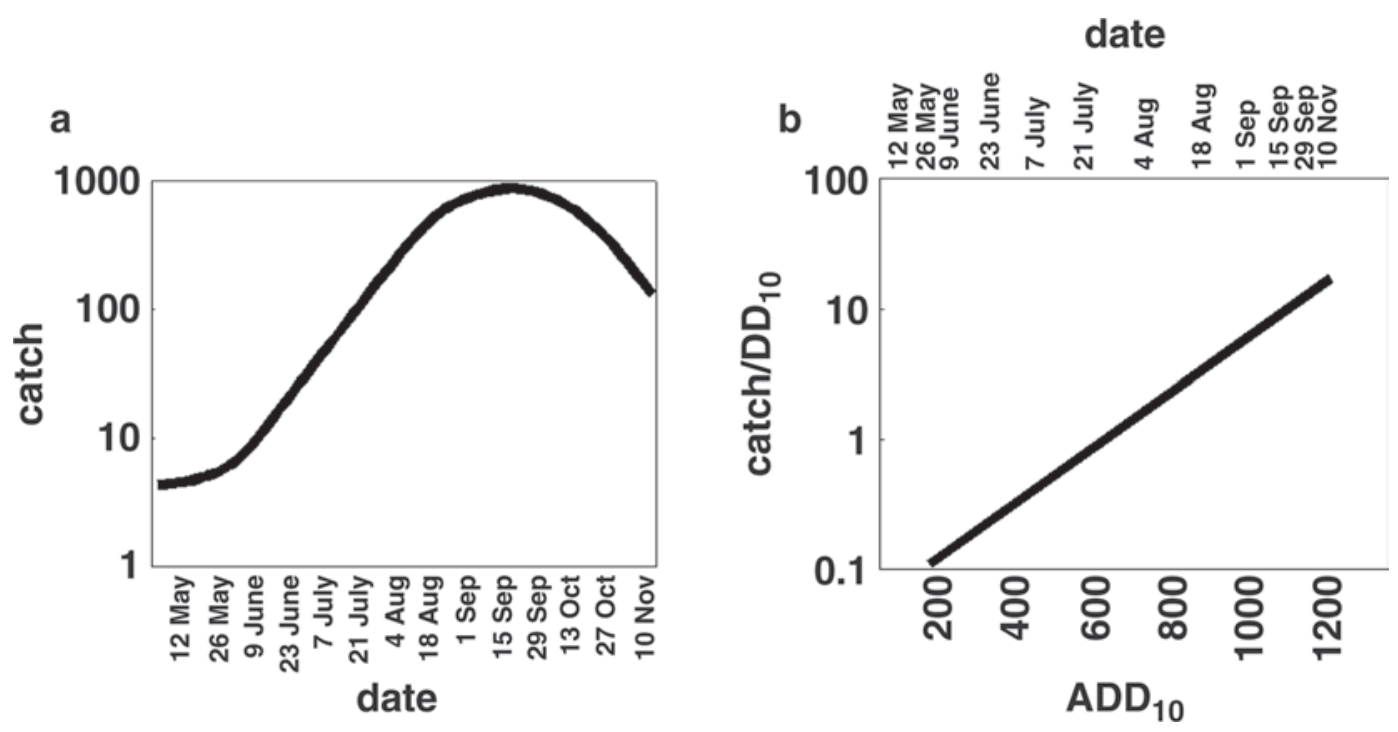

Figure 1. Relationship between modeled trap catch of a population growing exponentially $\left(r=0.005 /\right.$ degree day above $\left.10^{\circ} \mathrm{C} ; \mathrm{DD}_{10}\right)$ when plotted against date (a), and (b) the same catch data plotted as catch/ $\mathrm{DD}_{10}$ versus the accumulated degree days $(\mathrm{ADD} 10)$. The upper axis in panel $\mathrm{b}$ is the sampling dates spaced closer in spring and fall in terms of $\mathrm{ADD}_{10}$.

2009b) when cattle exhibit obvious signs of stress such as stamping, tail flicking, and head tossing (Eicher and Dailey, 2002; Mullens et al., 2006). Stable fly populations in this region achieve economical significance as pests only during the latter half of the growing season. Control measures taken by producers at this time typically include spraying pesticide, a method that is costly, wasteful, and potentially destructive of nontarget organisms and natural predators (Gerry et al., 2007) such as the macrochelid mites, Macrocheles muscaedomesticae (Scopoli), and Macrocheles subbadius (Berlese) (Mohsen et al., 1986), which are important in reducing stable fly eggs and larvae (Axtell, 1963).

The objective was to demonstrate the use of $r$ to test whether treated targets can affect stable fly populations on dairy farms in Ontario, Canada. The hypothesis was that if a sustained kill of a small proportion of the population could be achieved using attractive targets treated with permethrin, this should produce measurable reductions in $r$.

\section{MATERIALS AND METHODS}

\section{Study Locations}

This study was conducted in 2000 and 2001 on 6 dairy farms. The farms were similar in size $(\sim 40$ ha farms with $\sim 120$ cows) and landform, and all were located in a $12 \mathrm{~km} \times 5 \mathrm{~km}$ region along the north shore of Rice Lake near Keene, Ontario, Canada $\left(44^{\circ} 15^{\prime} \mathrm{N}\right.$, $78^{\circ} 15^{\prime} \mathrm{W}$ ), south of Peterborough. None of the farms had overwintering stable fly populations in 1999 to 2000 or 2000 to 2001, and each was recolonized by S. calcitrans between late May and early June of both years. Three farms were randomly assigned as nontreatment farms (designated farms 1, 2, and 3) and 3 as treatment farms (farms 4, 5, and 6).

\section{Sticky Card Traps}

Stable fly populations at each of the 6 farms were sampled both years with Coroplast (Great Pacific Enterprises Inc., Granby, Québec, Canada; a white corrugated twinwall polypropylene plastic sheeting used for signs and packaging) sticky card traps (Cilek, 2003; Beresford and Sutcliffe, 2006). Each card was $20.3 \mathrm{~cm}$ $\times 30.5 \mathrm{~cm}$ and was coated on both sides with TangleTrap (Tanglefoot Co., Grand Rapids, MI). Individual cards were mounted on a wooden stake and placed with the bottom edge $20 \mathrm{~cm}$ above the surrounding grass (Beresford and Sutcliffe, 2008). Five traps were deployed at each farm for $1 \mathrm{wk}$ at a time, then collected and replaced with fresh cards for the following week of sampling. Traps were placed near barnyard fences, salt licks, and watering troughs, about $30 \mathrm{~m}$ apart and away from farm machinery and livestock. For each sampling week, the number and sex of stable flies caught on each card were recorded. Sampling continued until the first full week with a mean temperature of $<10^{\circ} \mathrm{C}$, the stable fly's developmental threshold temperature (Pruess, 1983; Lysyk, 1993, 1998). This resulted in $10 \mathrm{wk}$ of data in 2000, from August 3 to October 5 (date is end 


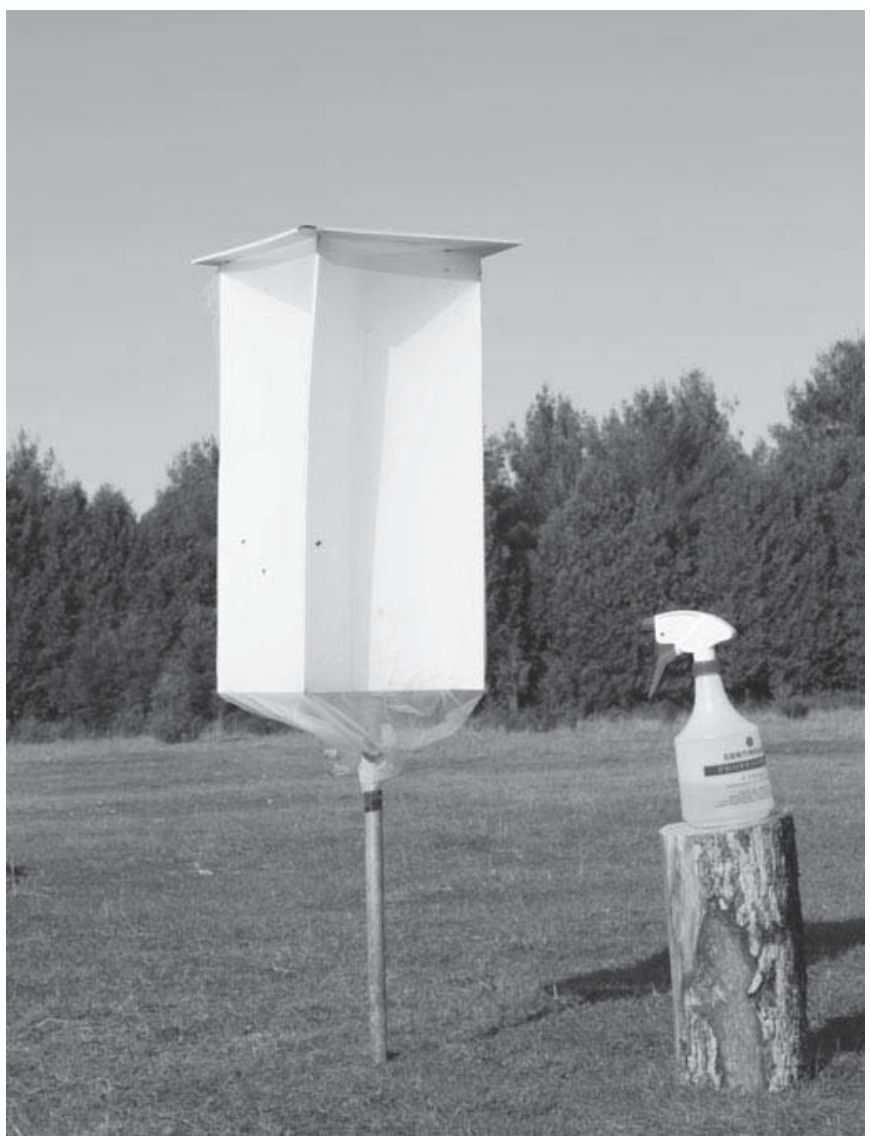

Figure 2. Configuration of treated targets intersecting panels and lid for weather protection, and construction. The spray bottle was used for applying Ectiban (Schering-Plough Canada Inc., PointeClaire, Québec, Canada) solution to the netting, which covered the entire target.

of each week; no data for farms 1 and 4 for September 7 week because of cattle damage to traps) and 9 wk of data in 2001, from August 22 to October 25.

\section{Treated Targets}

In 2001, 2 targets were placed on each farm on August 30. Each target (Figure 2) consisted of two $40 \mathrm{~cm} \times 60$ $\mathrm{cm}$ white Coroplast panels intersecting along their long $(60 \mathrm{~cm})$ axis, to create a crossed structure with four 20 $\mathrm{cm} \times 60 \mathrm{~cm}$ wings. The whole assembly was covered with a sleeve of white fabric netting ( $3 \mathrm{~mm}$ mesh size) and mounted $30 \mathrm{~cm}$ above the surrounding vegetation on a metal stake. A $40 \mathrm{~cm} \times 40 \mathrm{~cm}$ Coroplast lid was placed on each target to protect these from rain and sun.

At initial setup, the netting covering each of the 2 targets on treatment farms was soaked in a solution of 1 part Ectiban (Schering-Plough Canada Inc., PointeClaire, Québec; containing 240 g permethrin/L) to 10 parts water. Soaked nets were allowed to dry before being installed. From weighing the container of permethrin solution before and after treatment, each net took up approximately $0.84 \mathrm{~g}$ of permethrin. Nets were retreated weekly by hand spraying in situ with $35 \mathrm{~mL}$ of Ectiban diluted as above. The nets of the 2 targets at the untreated farms were soaked in distilled water at initial set-up and sprayed with $35 \mathrm{~mL}$ of distilled water once weekly thereafter. Criteria for target placement were the same as for the sticky cards (above). Targets were left in place at all farms until the end of the sampling period.

\section{Analysis}

During 2001, the first 2 wk provided a baseline for population estimates before any possible treatment effect of subsequent weeks. Instantaneous rates of stable fly population increase were obtained for all farms during both years by converting weekly sticky card catches to catch per DD (Beresford and Sutcliffe, 2009a) above a development threshold of $10^{\circ} \mathrm{C}\left(\mathrm{DD}_{10}\right)$. Degree days were calculated using the sine curve method (Baskerville and Emin, 1969; Allen, 1976) using daily maximum and minimum temperature data from the Peterborough Airport, which is about $15 \mathrm{~km}$ from the study region. The slope of the straight line fitted to the series defined by $\ln \left(\mathrm{N}_{\text {week } \mathrm{t}} / \mathrm{DD}_{10 \text { week } \mathrm{t}}\right)$, with $\mathrm{N}=$ trap catch for each sampling week $(\mathrm{t})$, yielded the $r_{\mathrm{DD} 10}$ for each farm for the periods sampled (Beresford and Sutcliffe, 2009a).

Differences in $r_{\mathrm{DD} 10}$ between treatment and nontreatment farms in 2001 were tested using multiple regression (Excel 2003, Microsoft Corp., Redmond, WA) in conjunction with a dummy or indicator variable (Aiken and West, 1991). The interaction between treatment and $\mathrm{ADD}_{10}$ was tested using the model

$$
y=\alpha+\beta x+\delta(x \times D)+\varepsilon,
$$

where $y=\ln$ (number of flies trapped), $x=\mathrm{ADD}_{10}$ (from January), $\alpha$ and $\beta$ are constants, $\delta$ is the difference in slopes between treated and untreated farm populations, $D$ is the dummy variable ( 1 applied to treatment farms and 0 applied to nontreatment farms), and $\varepsilon$ is the error. In this analysis, a regression line was fitted to the $\ln \mathrm{N} / \mathrm{DD}_{10}$ versus $\mathrm{ADD}_{10}$ trap catch data for all farms. The resulting residuals were fitted to the treatment farm data only. That is, lntrap weekly catches at all the farms was the dependent variable, and the 2 independent variables were $\mathrm{ADD}_{10}$ and $\mathrm{D} \times \mathrm{ADD}_{10}$. This meant testing whether $\delta=0$, in the following:

$$
\begin{gathered}
y=\alpha+\beta x+\varepsilon \text { nontreatment farms; } \mathrm{D}=0, \text { and } \\
y=\alpha+(\beta+\delta) x+\varepsilon \text { treatment farms; } \mathrm{D}=1 .
\end{gathered}
$$




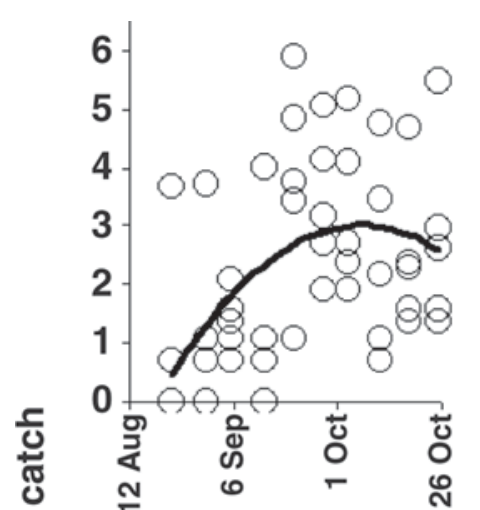

Farm 1

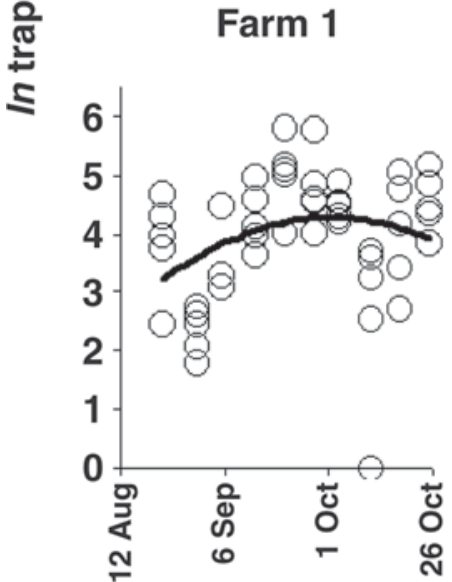

Farm 4

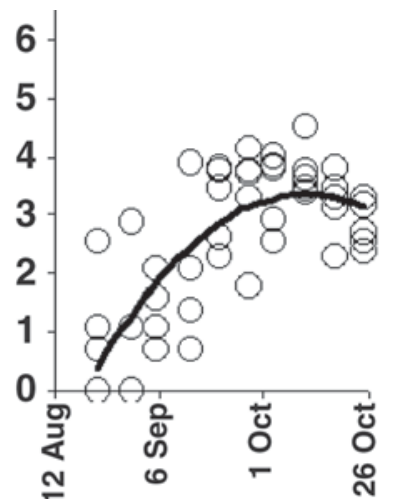

Farm 2

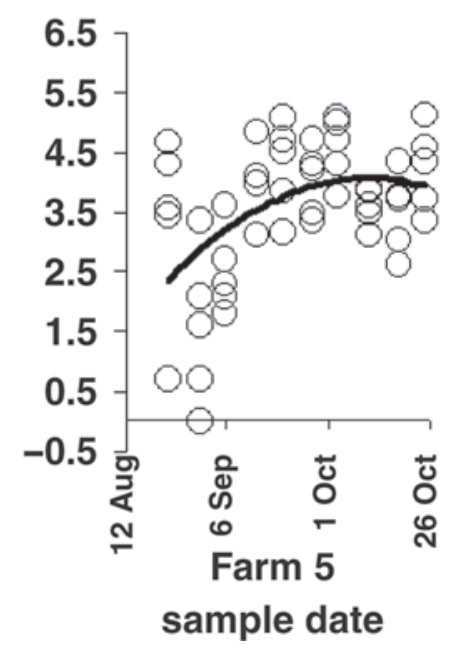

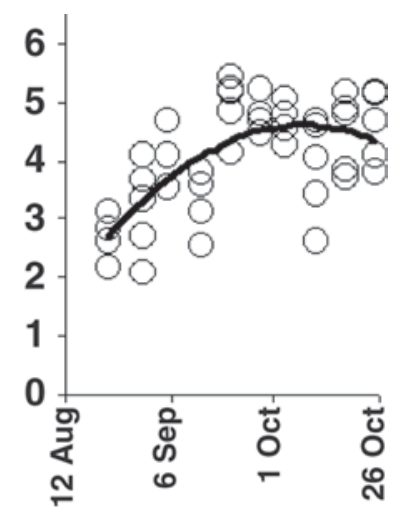

Farm 3

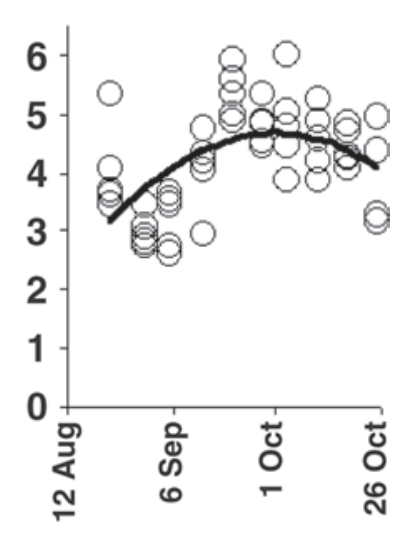

Farm 6

Figure 3. Weekly counts $(\ln \mathrm{N})$ of stable flies caught on 5 monitoring traps each week at each farm in 2001 . Two attractive targets were placed at each farm. Only the targets on farms 4, 5 , and 6 (lower row) were treated with permethrin. Circles are each of the 5 trap catches in each week. The quadratic trend line was fitted using least squares.

This method tested for possible effects of the treated targets on $r_{\mathrm{DD} 10}$.

Because trap catch was a relative number based on trap location within each farm, the absolute number of stable flies caught each week cannot be used to compare population size between farms. For this reason there was no interest in testing differences between y-intercepts between treatment and control farms, but testing was limited to whether slopes differed between treatment and control farms. Population growth rates were also analyzed at these 2 groups of farms in 2000 when no targets were installed.

\section{RESULTS}

Catch numbers from the monitoring traps followed the same general pattern at each farm in both 2000 and 2001 (Figure 3; patterns typical): increasing in summer and gradually peaking by late September, then decreas- ing. Stable fly populations grew exponentially at all farms over both 2000 and 2001 (Table 1; Figures 4 and $5)$ until limited by cold temperatures.

In 2000, the year treated targets were not deployed, populations grew at about the same rates at the 2 groups of farms: mean $r_{\mathrm{DD} 10}=0.015$ and 0.012 at nontreatment and treatment farms, respectively (Table 1). In contrast, during 2001, the year treated targets were deployed, populations grew more slowly at the 3 farms where the treated targets were installed: mean $r_{\mathrm{DD} 10}=$ 0.013 and 0.0088 at nontreatment and treatment farms, respectively (Tables 1 and 2).

Stable fly catches in 2001 varied among the 6 study farms, with no pattern in absolute productivity being discernible between treated and untreated farms. The total number of flies caught on sticky card traps in 2001 ranged from 1,058 on farm 2 (nontreatment farm) to 4,900 on farm 6 (treatment farm). 

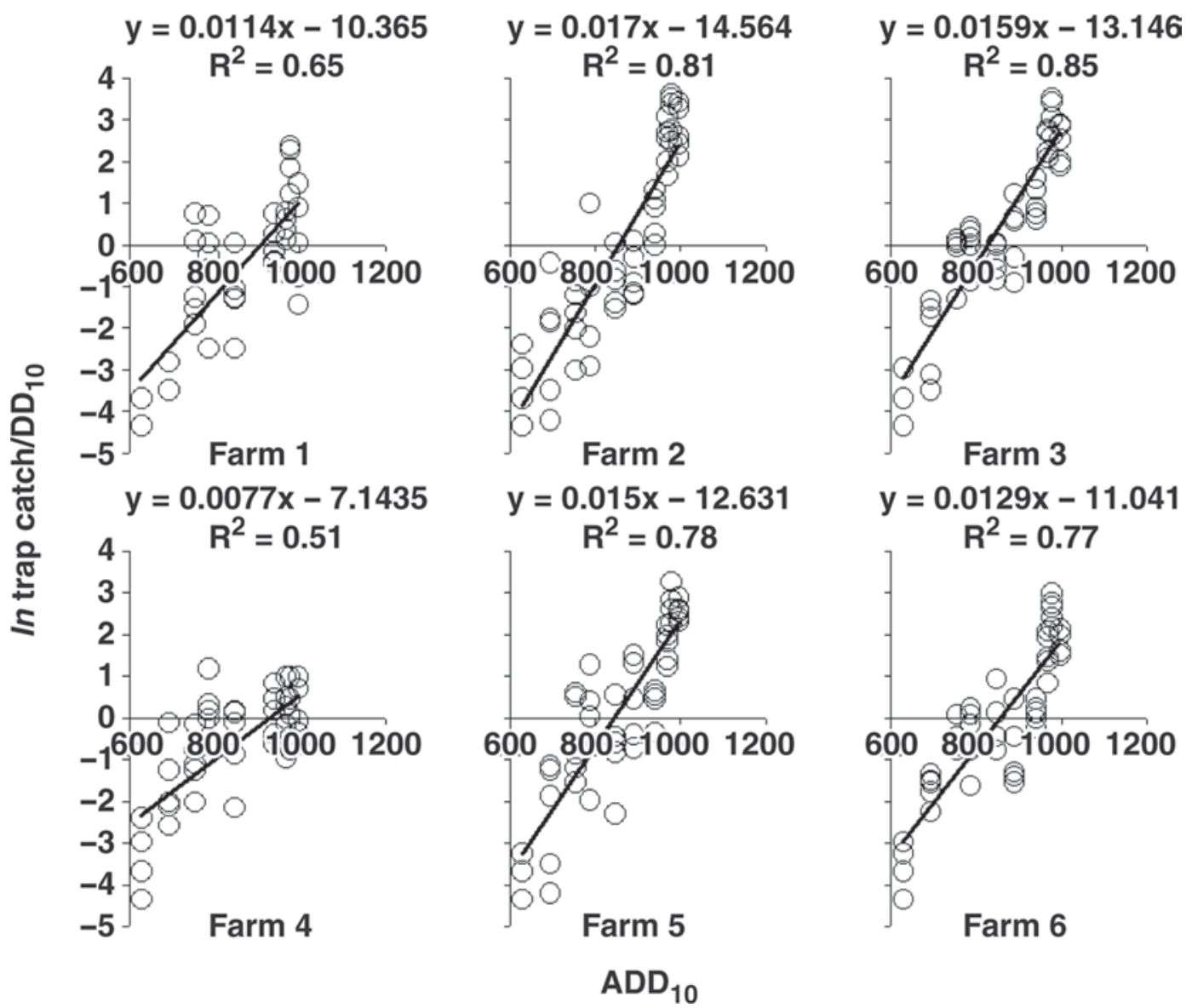

Figure 4. Weekly counts and regression lines of stable flies caught in 2000 (5 traps/farm per week; circles are each trap catch), expressed as $\ln \mathrm{N} / \mathrm{DD}_{10}$ versus accumulated degree days above $10^{\circ} \mathrm{C}\left(\mathrm{ADD}_{10}\right)$. $\mathrm{N}$ is weekly trap catch, and $\mathrm{DD}_{10}$ are the degree days above $10^{\circ} \mathrm{C}$ for each week.

\section{DISCUSSION}

Our results from 2001 suggest targets treated with permethrin lowered the $r$ of stable fly populations on the treated farms. It is possible that farms with treated targets were simply inherently less productive of stable flies than farms with untreated targets. However, stable fly growth rates did not differ on these 2 farm groups the previous year when targets were not installed.

We expect that the treated targets would not have been equally effective at each farm because of differences in target location. Factors relating to individual farms, such as farm layout, location of calf hutches, or transfer of cattle to different pastures, produce farmspecific effects on monitoring trap catches. In addition, machinery, cattle curiosity, and farm layout all interfere with the placement of targets and traps (Beresford and Sutcliffe, 2006). These were often relegated to suboptimal locations away from where stable fly density was expected highest because of the needs of the producer. Consequently, it can be difficult to compare the effec- tiveness of control measures on commercial farms based on absolute catch data, either between farms or between years. Comparing treatments using $r$ eliminates many site problems because $r$ is a relative measure and is less affected by farm routine and trap placement specifics. As a test metric, $r$ is not relevant for comparing short-term control measures that have a goal of rapid pest reduction. It is best used for comparing long-term control strategies, such as those that test management methods or long-term control measures (Stark et al., 2007).

It is probable that stable flies were dispersing between study farms and those in the surrounding region. The effect of dispersal between farms would be to dilute any effect that the treated targets would have had on any particular farm and make it more difficult to observe these effects in terms of $r$ (Killeen et al., 2003). That we could measure differences in $r$ on farms outfitted with only 2 treated targets is further support for this trait as a test metric. 
Table 1. Summary of the linear regressions of weekly trap catch $(\mathrm{N})$ of stable flies per degree days above $10^{\circ} \mathrm{C}\left(\mathrm{DD}_{10}\right)$ each day against accumulated degree days $\left(\mathrm{ADD}_{10} ; \ln (\mathrm{N}+1) / \mathrm{DD}_{10} \mathrm{vs} . \mathrm{ADD}_{10}\right)$ for $10 \mathrm{wk}$ of 2000 and $2001^{1}$

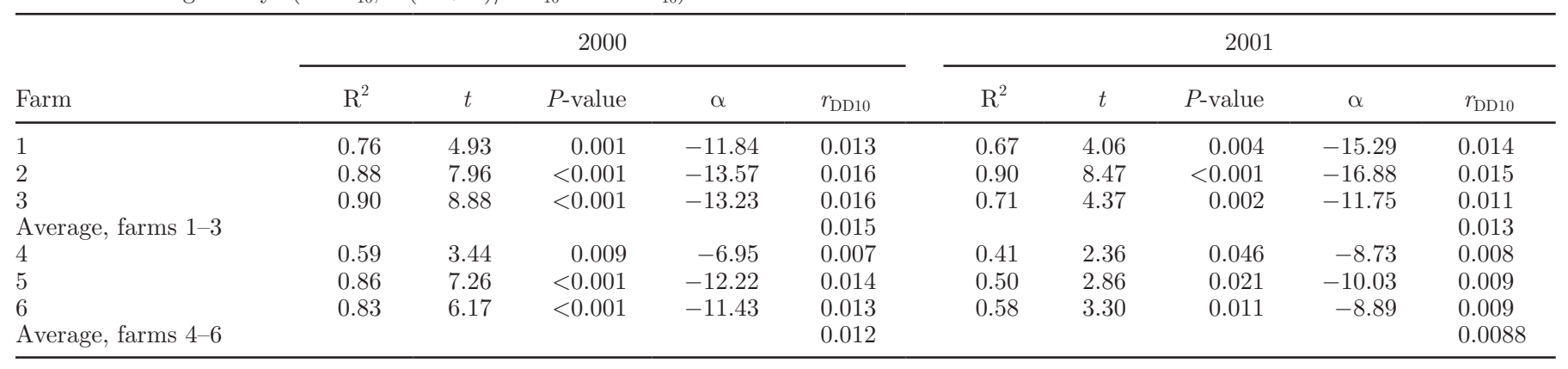

${ }^{1}$ The $\mathrm{DD}_{10}$ based population growth rate $\left(r_{\mathrm{DD} 10}\right)$ is the slope of the regression line, and $\alpha$ is the y-intercept. Targets (untreated on farms 1,2 , and 3 and treated with permethrin on farms 4,5 , and 6) were installed in 2001 only. $\mathrm{R}^{2}$ is the regression coefficient, tested using $t$, a test statistic based on the $t$ distribution.

The treated targets presumably worked by inducing stable flies to land on the netting, where they picked up a lethal dose of insecticide. This is supported by the observation of small numbers of dead stable flies and other muscids under treated targets. Permethrin in this form takes several hours to kill stable flies (Hogsette and Ruff, 1996); the dead flies may have been using the targets as long-term (e.g., overnight) resting sites.

Beresford and Sutcliffe (2006) showed that female stable flies caught on Coroplast sticky card traps on dairy farms were predominantly $(>80 \%)$ unmated, nulliparous females. Any kills from the Coroplast-based targets were likely from this subpopulation on treatment farms. Female stable flies require up to 5 blood meals to complete their first gonotrophic cycle and require an average of 3 more blood meals for each subsequent oviposition (Moobola and Cupp, 1978). Targeting the early nulliparous stages kills them before they are able to reproduce and limits the number of blood meals they take from cattle. This is a possible benefit that control methods based on targeting immature stages (Schmidtmann, 1991) or ovipositing flies would not have.

Permethrin-treated targets were not as rapidly selfdepleting as sticky traps, maintaining $70 \%$ of killing capacity after 10 wk (Hogsette and Ruff, 1996). In comparison, sticky targets lose effectiveness with the accumulation of trapped flies over a few days to $1 \mathrm{wk}$ (Beresford and Sutcliffe, 2006).

Previous workers have investigated attractive sticky traps as the basis of methods to control on-farm stable fly populations (Koehler and Patterson, 1982; Rugg, 1982; Kaufman et al., 2005); insecticide- or chemosterilant-treated traps and targets of various designs were used to kill stable flies (Tseng et al., 1986; Hogsette and Ruff, 1996; Foil and Younger, 2006). These methods can require intensive efforts to implement if designed to deal with the established populations of stable flies that exist year-round in many areas.

In temperate areas such as Ontario where stable fly populations grow gradually to pest proportions each year, economic impact is typically limited to the later half of the growing season (Taylor et al., 2007; Beresford and Sutcliffe, 2009b). Our results suggest that by achieving a consistent and sustained kill of a proportion of stable flies on a farm during the growing season, it should be possible to use some type of a pesticidetreated target configuration to slow the growth of pest populations. The treated targets that were described could be one component of a long-term management program. In particular, on more northern farms this

Table 2. Comparison of population growth rate in terms of degree days above $10^{\circ} \mathrm{C}\left(r_{\mathrm{DD} 10}\right)$ on treatment and nontreatment farms in 2000 (no targets deployed) and 2001 (2 targets/farm $)^{1,2}$

\begin{tabular}{|c|c|c|c|c|c|c|c|c|c|}
\hline Year & \multicolumn{4}{|c|}{ Multiple regression } & \multicolumn{5}{|c|}{ Test of interaction } \\
\hline 2000 & 0.88 & 94.5 & 2,57 & $<0.001$ & $x \times D$ & 0.00008 & 0.0003 & 0.31 & 0.75 \\
\hline
\end{tabular}

${ }^{1}$ The effects of treated targets were analyzed using multiple regression with a dummy variable $(D)$ to test for interaction between $l n$ of total stable flies caught on sticky traps each week versus accumulated degree days $\left(\mathrm{ADD}_{10} ; x\right)$. The lack of a significant interaction effect $(x \times D$ in the table) for 2000 means that the population growth rates ( $r_{\mathrm{DD} 10}$ measured as slope) at treatment farms were similar to nontreatment farms, whereas the significant interaction in 2001 means populations grew more slowly on treatment farms that year.

${ }^{2} \mathrm{R}^{2}$ is the regression coefficient, and $\mathrm{F}$ and $t$ are test statistics based on the $\mathrm{F}$ and $t$ distributions used for $\mathrm{R}^{2}$ and $\beta$, respectively. 


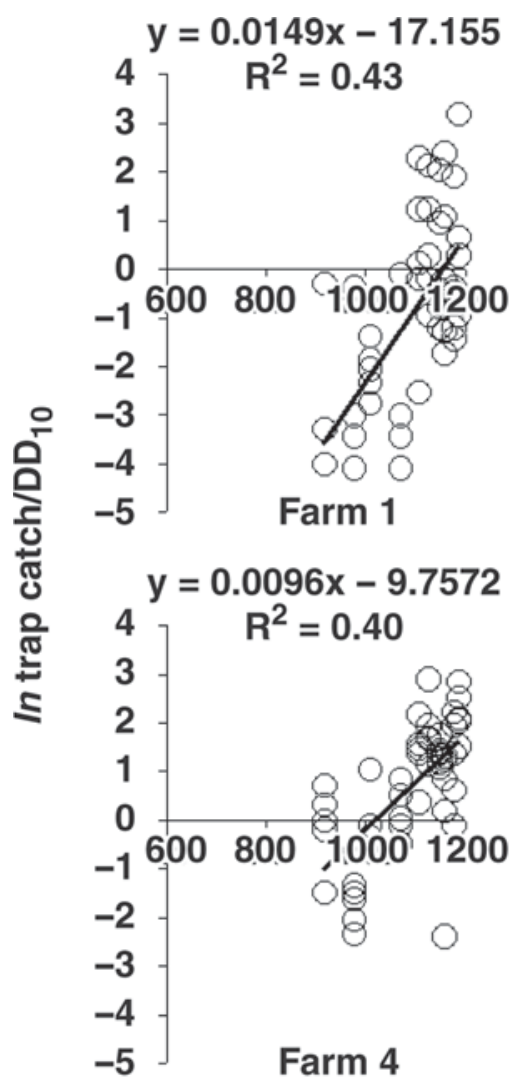

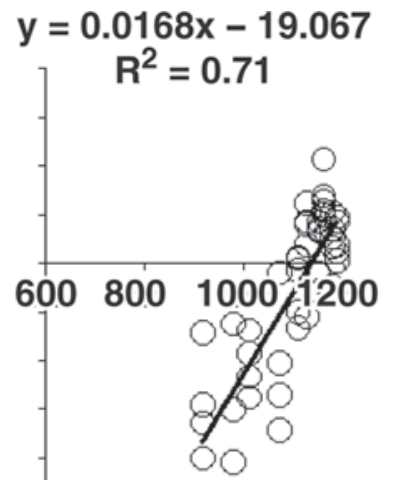

Farm 2
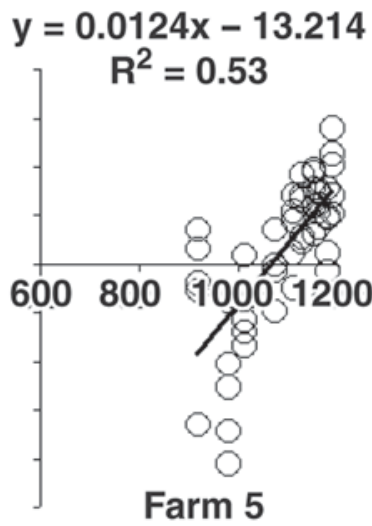

$\mathrm{ADD}_{10}$

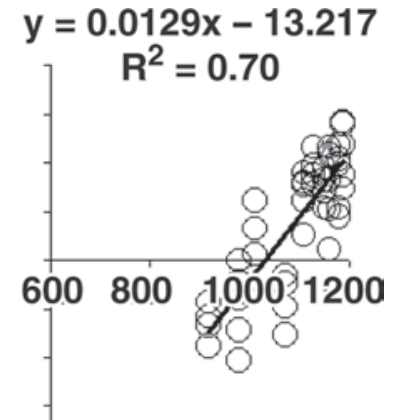

Farm 3

$y=0.0103 x-10.266$

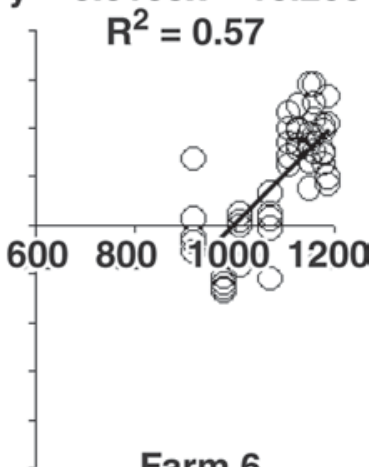

Farm 6

Figure 5. Weekly counts and regression lines of stable flies caught in 2001 (5 traps/farm per week; circles are each trap catch), expressed as $\ln \mathrm{N} / \mathrm{DD}_{10}$ versus accumulated degree days above $10^{\circ} \mathrm{C}\left(\mathrm{ADD}_{10}\right) . \mathrm{N}$ is weekly trap catch, and $\mathrm{DD}_{10}$ are the degree days above $10^{\circ} \mathrm{C}$ for each week. Two attractive targets treated with permethrin were installed at farms 4,5 , and 6 (lower row, Figure 3 ).

might significantly shorten the period when the pest is economically significant, before the onset of cold temperatures.

\section{ACKNOWLEDGMENTS}

The authors thank the cooperating members of the Dairy Farmers of Ontario from Peterborough County who generously allowed us access to their farms and Janet Buckley for her tireless help in the field. This research was supported in part by a Natural Sciences and Engineering Research Council of Canada (NSERC) Research Grant to JFS and by an NSERC Graduate Fellowship to DVB. We also gratefully acknowledge the insightful comments made by the anonymous reviewers of this paper.

\section{REFERENCES}

Aiken, L. S., and S. G. West. 1991. Multiple Regression: Testing and Interpreting Interactions. SAGE Publications Inc., London, UK.
Allen, J. C. 1976. A modified sine wave method for calculating degree days. Environ. Entomol. 5:388-396.

Axtell, R. C. 1963. Effect of Macrochelidae (Acarina: Mesostigmata) on house fly production from dairy cattle manure. J. Econ. Entomol. 56:317-321.

Baskerville, G. L., and P. Emin. 1969. Rapid estimation of heat accumulation from maximum and minimum temperatures. Ecology 50:514-517.

Beresford, D. V., and J. Sutcliffe. 2006. Studies on the effectiveness of Coroplast sticky traps for sampling stable flies, Stomoxys calcitrans (Diptera: Muscidae), including a comparison to Alsynite. J. Econ. Entomol. 99:1025-1035.

Beresford, D. V., and J. Sutcliffe. 2008. Stable fly (Stomoxys calcitrans: Diptera, Muscidae) trap response to changes in effective trap height caused by growing vegetation. J. Vector Ecol. 33:40-45.

Beresford, D. V., and J. Sutcliffe. 2009a. Sampling designs of insect time series data: Are they all irregularly spaced? Oikos 118:115121.

Beresford, D. V., and J. Sutcliffe. 2009b. Local infestation or long distance migration? The seasonal re-colonization of dairy farms by Stomoxys calcitrans (Diptera: Muscidae) in south-central Ontario. J. Econ. Entomol. 102:788-798.

Birch, L. C. 1948. The intrinsic rate of natural increase of an insect population. J. Anim. Ecol. 17:15-25.

Campbell, J. B., I. L. Berry, D. J. Boxler, R. L. David, D. C. Clanton, and G. H. Deutscher. 1987. Effects of stable flies (Diptera: Muscidae) on weight gain and feed efficiency of feedlot cattle. J. Econ. Entomol. 80:117-119. 
Catangui, M. A., J. B. Campbell, G. D. Thomas, and D. J. Boxler. 1997. Calculating economic injury levels for stable flies (Diptera: Muscidae) on feeder heifers. J. Econ. Entomol. 90:6-10.

Cilek, J. E. 2003. Attraction of colored plasticized corrugated boards to adult stable flies, Stomoxys calcitrans (Dipteral: Muscidae). Fla. Entomol. 86:420-423.

Dougherty, C. T., F. W. Knapp, P. B. Burrus, D. C. Willis, J. G. Burg, P. L. Cornelius, and N. W. Bradley. 1993. Stable flies (Stomoxys calcitrans L.) and the behavior of beef cattle. Appl. Anim. Behav. Sci. 35:215-233.

Eicher, S. D., and J. W. Dailey. 2002. Indicators of acute pain and fly avoidance behaviors in Holstein calves following tail-docking. J. Dairy Sci. 85:2850-2858.

Foil, L. D., and C. D. Younger. 2006. Development of treated targets for controlling stable flies (Diptera: Muscidae). Vet. Parasitol. $137: 311-315$

Frazer, B. D. 1972. Population dynamics and recognition of biotypes in the pea aphid (Homoptera: Aphididae). Can. Entomol. 104:17291733.

Gerry, A. C., N. G. Peterson, and B. A. Mullens. 2007. Predicting and controlling stable flies on California dairies. ANR Publication 8258. University of California Agriculture and Natural Resources Communication Services, Oakland.

Hogsette, J. A., and J. P. Ruff. 1996. Permethrin-impregnated yarn: Longevity of efficacy and potential use on cylindrical fiberglass stable fly (Diptera: Muscidae) traps. J. Econ. Entomol. 89:15211525 .

Hughes, R. D. 1962. A method for estimating the effects of mortality on aphid populations. J. Anim. Ecol. 31:389-396.

Kaufman, P. E., D. A. Rutz, and S. Frisch. 2005. Large sticky traps for capturing house flies and stable flies in dairy calf greenhouse facilities. J. Dairy Sci. 88:176-181.

Killeen, G. F., B. G. J. Knols, and W. Gu. 2003. Taking malaria transmission out of the bottle: Implications of mosquito dispersal for vector control interventions. Lancet Infect. Dis. 3:23-29.

Koehler, P. G., and R. S. Patterson. 1982. Stable fly control with fiberglass panels. IFAS, University of Florida Cooperative Extension Service Livestock Protection Pointer, 14. University of Florida, Gainesville.

Lysyk, T. J. 1993. Seasonal abundance of stable flies and house flies (Diptera: Muscidae) in dairies in Alberta, Canada. J. Med. Entomol. 30:888-895.
Lysyk, T. J. 1998. Relationships between temperature and life-history parameters of Stomoxys calcitrans (Diptera: Muscidae). J. Med. Entomol. 35:107-119.

Mohsen, Z. H., S. H. Mahood, S. I. Al-dulaimi, and A. M. Al-faisal. 1986. Comparative toxicity of pesticides against house fly Musca domestica and predator mite Macrocheles muscaedomesticae under laboratory conditions. J. Behav. Sci. Res. 17:207-214.

Moobola, S. M., and E. W. Cupp. 1978. Ovarian development in the stable fly, Stomoxys calcitrans, in relation to diet and juvenile hormone control. Physiol. Entomol. 3:317-321.

Mullens, B. A., K. Lii, Y. Mao, J. A. Meyer, N. G. Peterson, and C. E. Szijj. 2006. Behavioural responses of dairy cattle to Stomoxys calcitrans in an open field environment. Med. Vet. Entomol. 20:122-137.

Pruess, K. P. 1983. Day-degree methods for pest management. Environ. Entomol. 12:613-619.

Rugg, D. 1982. Effectiveness of Williams traps in reducing the numbers of stable flies (Diptera: Muscidae). J. Econ. Entomol. $75: 857-859$

Schmidtmann, E. T. 1991. Suppressing immature house and stable flies in outdoor calf hutches with sand, gravel, and sawdust bedding. J. Dairy Sci. 74:3956-3960.

Stark, J. D., and J. E. Banks. 2003. Population-level effects of pesticides and other toxicants on arthropods. Annu. Rev. Entomol. 48:505519 .

Stark, J. D., R. L. Sugayama, and A. Kovaleski. 2007. Why demographic and modeling approaches should be adopted for estimating the effects of pesticides on biocontrol agents. BioControl 52:365374.

Taylor, D. B., and D. R. Berkebile. 2006. Comparative efficiency of six stable fly (Dipteral: Muscidae) traps. J. Econ. Entomol. 99:14151419 .

Taylor, D. B., D. R. Berkebile, and P. J. Scholl. 2007. Stable fly dynamic in eastern Nebraska in relation to climatic variables. J. Med. Entomol. 44:765-771.

Tseng, J. M., J. A. Hogsette, and R. W. Patterson. 1986. Effect of yarn on attractiveness of the William's trap to Stomoxys calcitrans (Diptera: Muscidae) adults. Fla. Entomol. 69:261-263. 